\title{
Correction to: Evaluation of lifestyle risk factor differences in global patterns of breast cancer mortality and DALYs during 1990-2017 using hierarchical age-period-cohort analysis
}

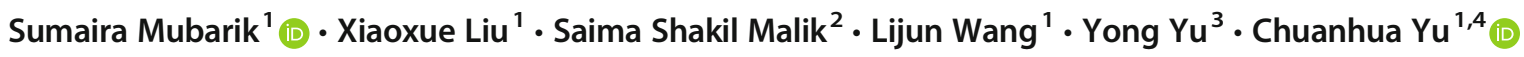 \\ Published online: 31 May 2021 \\ (C) Springer-Verlag GmbH Germany, part of Springer Nature 2021
}

Correction to: Environmental Science and Pollution Research https://doi.org/10.1007/s11356-021-14165-1

The correct images of Figs. 1, 2, 3 and 4 are presented in this paper.

The original article has been corrected.

The online version of the original article can be found at https://doi.org/ $10.1007 / \mathrm{s} 11356-021-14165-1$

Sumaira Mubarik sumairaawan86@gmail.com

$\triangle$ Chuanhua Yu yuchua@whu.edu.cn

Xiaoxue Liu liuxx019@163.com

Saima Shakil Malik saimamalik25@yahoo.com

Lijun Wang

wanglj1003@163.com
Yong $\mathrm{Yu}$

yongyu@hbmu.edu.cn

1 Department of Epidemiology and Biostatistics, School of Health Sciences, Wuhan University, Wuhan 430071, China

2 Department of Zoology, University of Gujrat, Gujrat 50700, Pakistan

3 School of Public Health and Management, Hubei University of Medicine, 30\# South Renmin Road, Shiyan 442000, Hubei, China

4 Global Health Institute, Wuhan University, Wuhan 430071, China 

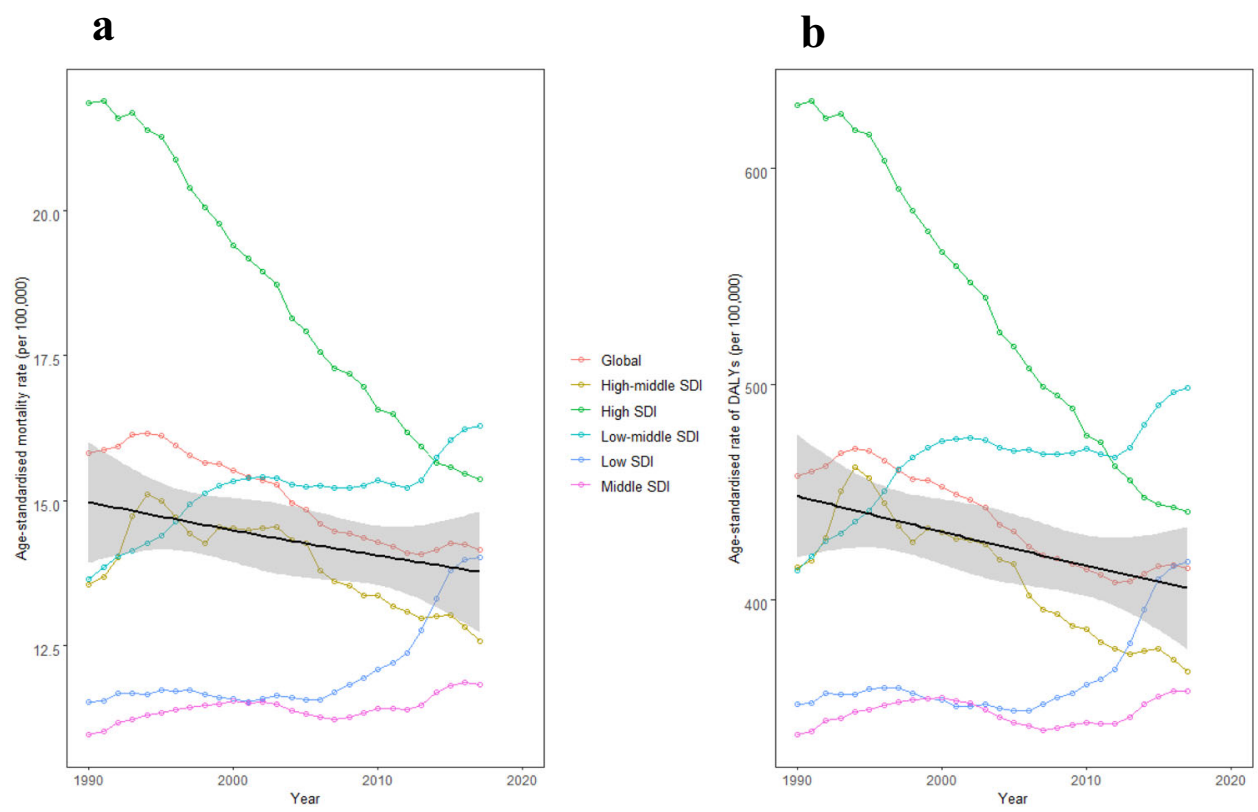

Fig. 1

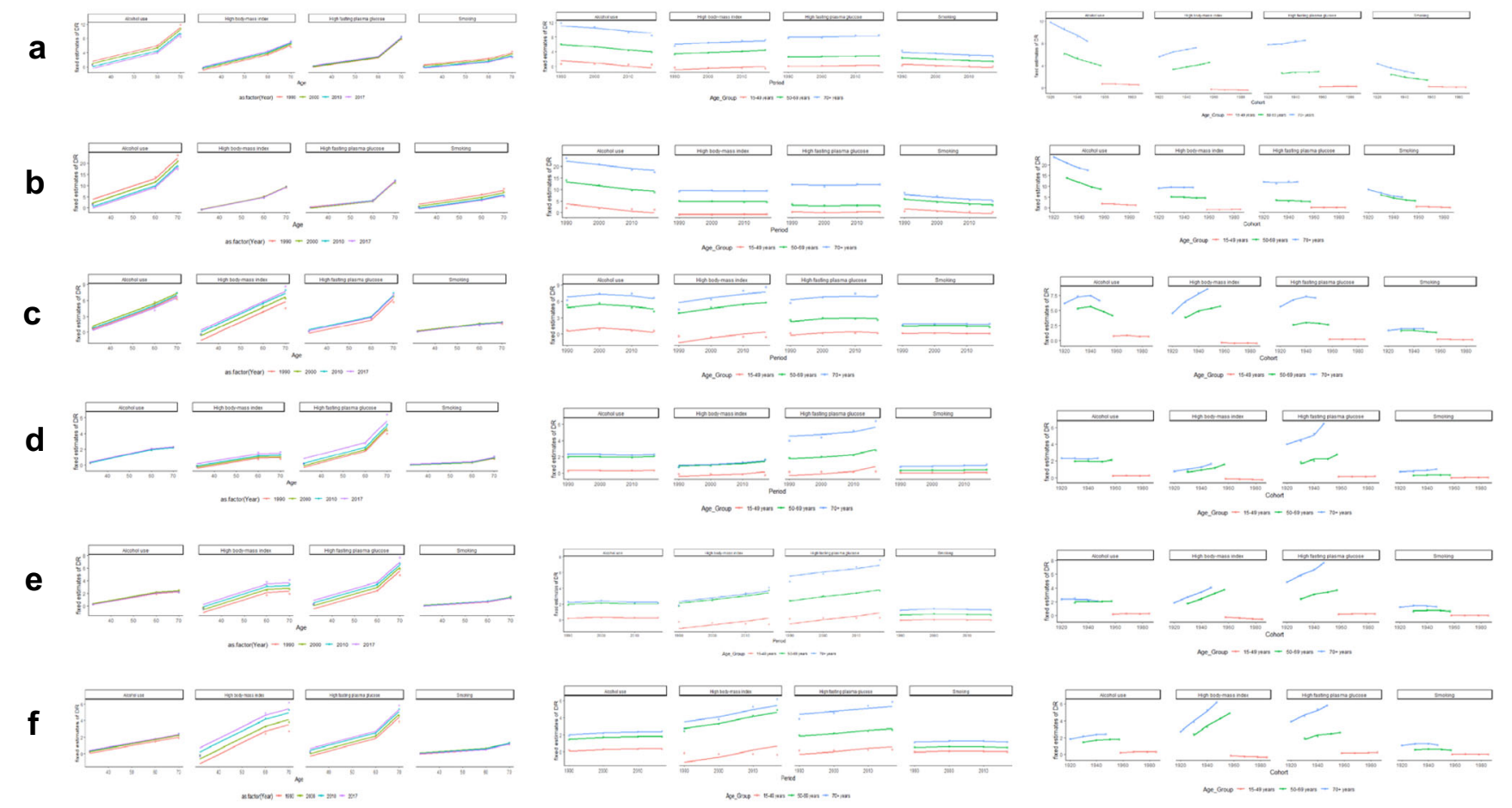

Fig. 2 
a
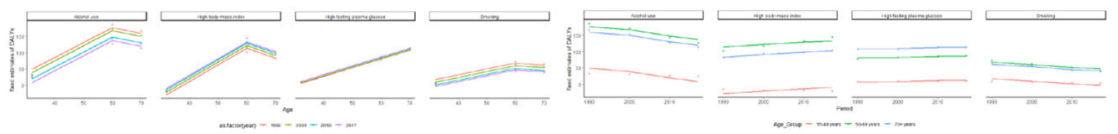

b
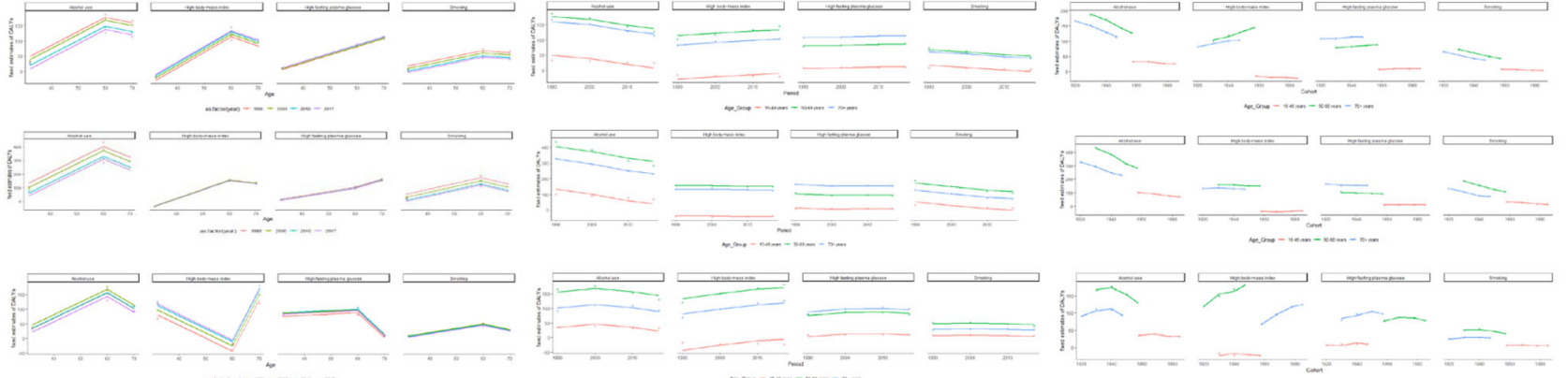

d
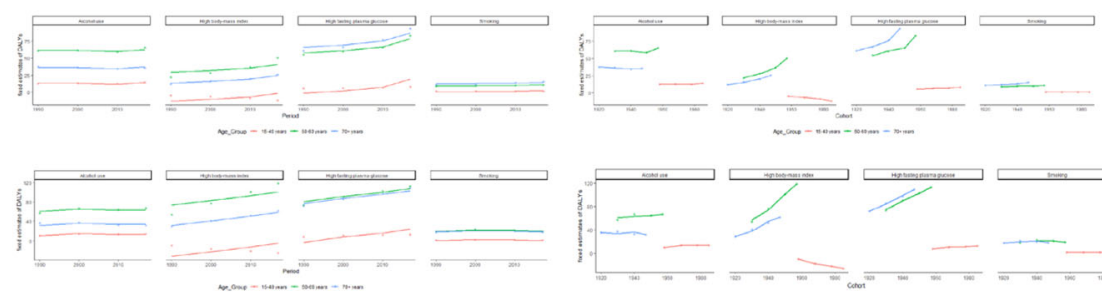

e
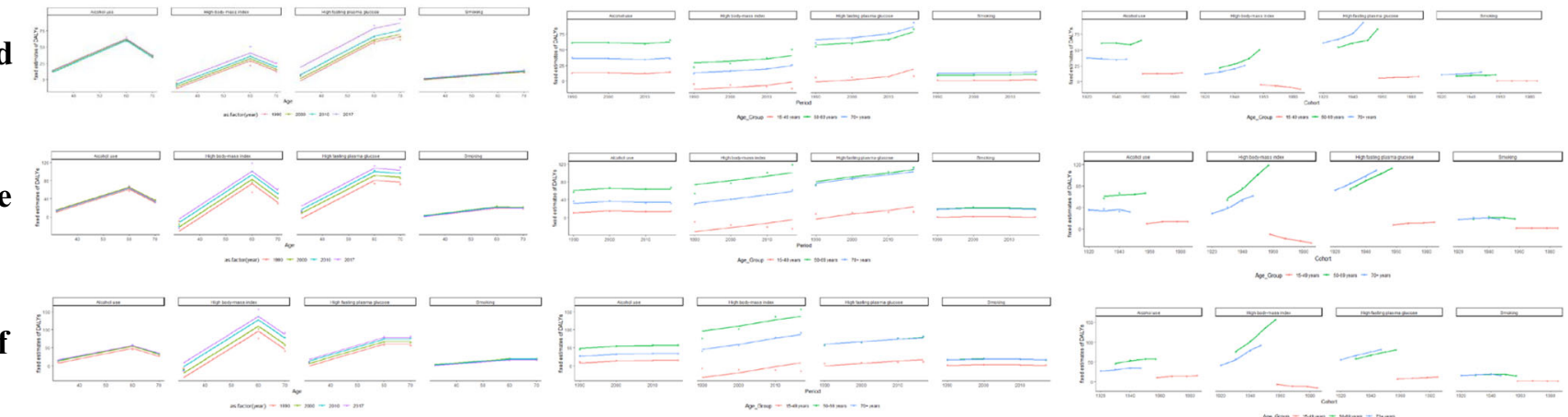

Fig. 3

a

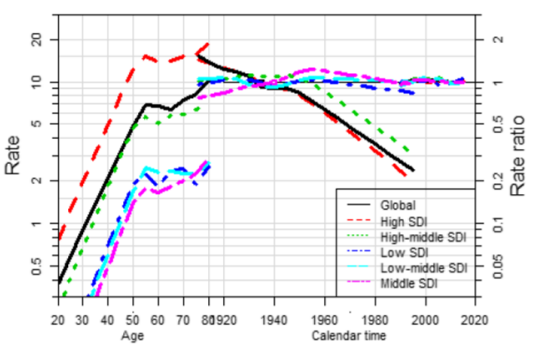

b

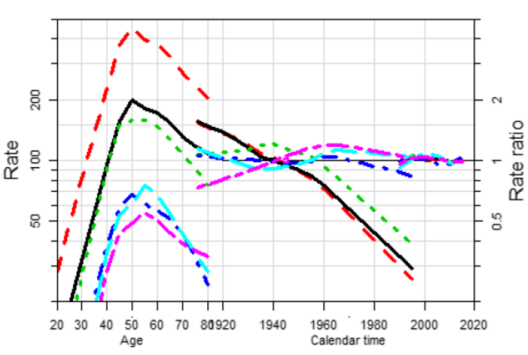

High fasting plasma glucose

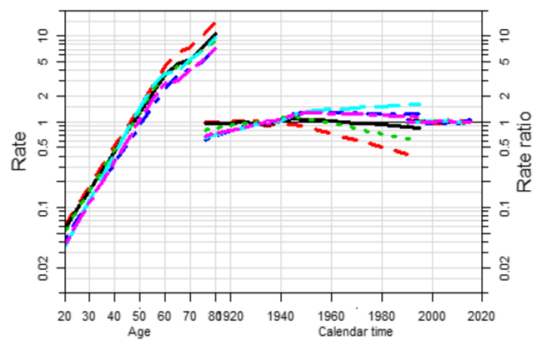

High fasting plasma glucose

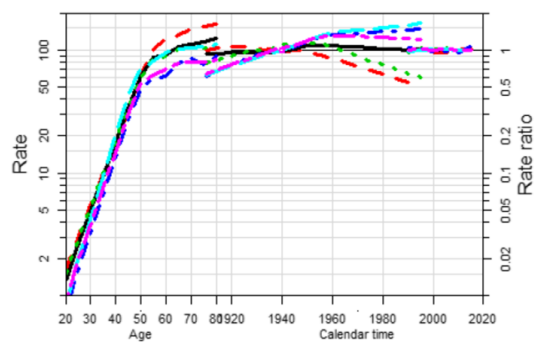

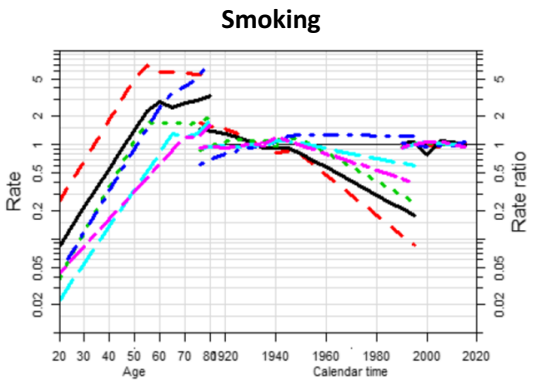

Smoking

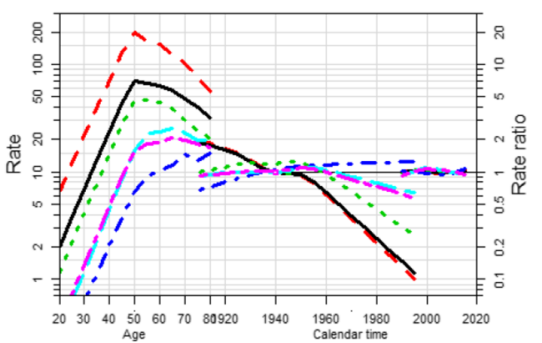

Fig. 4

Publisher's note Springer Nature remains neutral with regard to jurisdictional claims in published maps and institutional affiliations. 